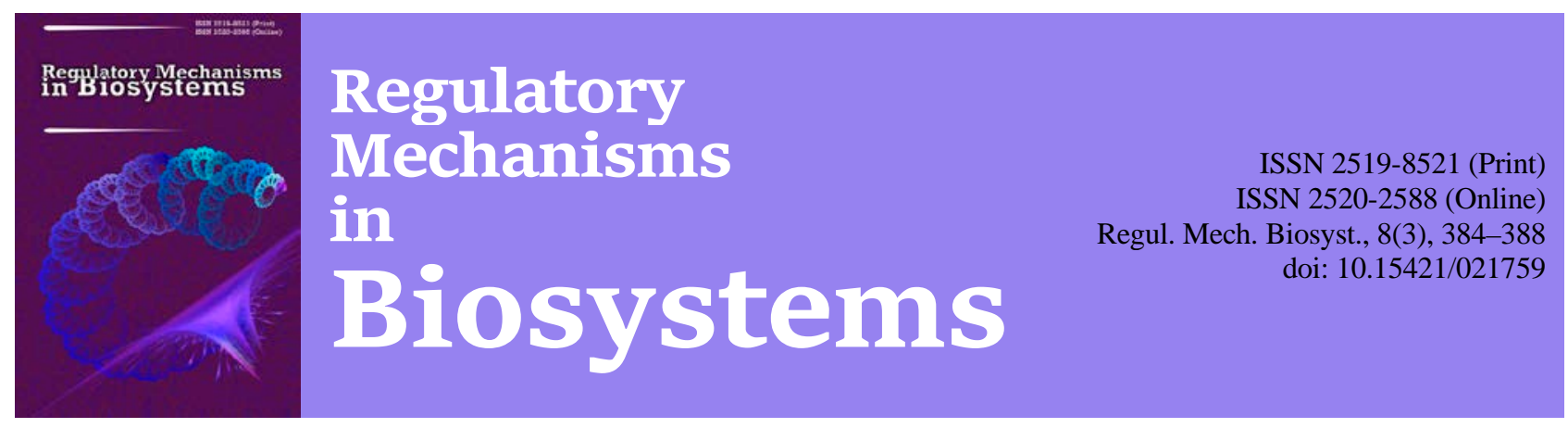

\title{
Biotype characterization of Staphylococcus aureus isolated from milk and dairy products of private production in the western regions of Ukraine
}

\author{
M. D. Kukhtyn*, Y. V. Horyuk**, V. V. Horyuk**, T. Y. Yaroshenko***, O. I. Vichko*, O. S. Pokotylo* \\ *Ternopil Ivan Puluj National Technical University, Ternopil, Ukraine \\ **State Agrarian and Engineering University in Podilya, Kamianets-Podilskyi, Ukraine \\ ***I. Y. Horbachevsky Ternopil State Medical Universi, Ternopil, Ukraine
}

\section{Article info}

Received 07.07.2017

Received in revised form 12.08.2017

Accepted 15.08.2017

Ternopil Ivan Puluj National

Technical University, Ruska Str.

56, Ternopil, 46001, Ukraine.

Tel.: +38-097-239-20-57.

E-mail: kuchtynnic@gmail.com

State Agrarian and Engineering

University in Podilya,

Schevchenko Str., 13,

Kamianets-Podilskyi, 32300,

Ukraine.

Tel.: +38-097-661-79-64.

E-mail: goruky@ukr.net

I. Horbachevsky Ternopyl State Medical University, Majdan Voli, 1,

Ternopil, 46001, Ukraine.

Tel.: +38-097-854-87-81.

E-mail:

yaroshenkotya@tdmu.edu.ua
Kukhtyn, M. D., Horyuk, Y. V., Horyuk, V. V., Yaroshenko, T. Y., Vichko, O. I., \& Pokotylo, O. S. (2017). Biotype characterization of Staphylococcus aureus isolated from milk and dairy products of private production in the western regions of Ukraine. Regulatory Mechanisms in Biosystems, 8(3), 384-388. doi: 10.15421/021759

Prevention of foodborne diseases is a priority for the world health system. In the process of manufacturing milk and dairy products, the most important factor compromising their safety is seeding with a conditionally pathogenic and pathogenic microflora. Salmonella, Escherichia coli, Listeria and other microorganisms that reproduce in dairy products without changing their organoleptic properties are a particular danger. Staphylococcus aureus is an opportunistic, conditionally pathogenic microorganism that often contaminates raw milk and dairy products. The aim of the research presented in this article was to determine the dissemination of $S$. aureus in milk and milk products of household production in the western regions of Ukraine, to identify the biotypes of $S$. aureus, production of enterotoxins and the presence of methicillin-resistant strains. S. aureus was isolated on BD Baird-Parker Agar. The biotypes of S. aureus were determined according to Meer. The determination of MRSA was carried out on the chromogenic Agar chromID MRSA ("Biomerioux", Russia). The mecA gene was determined using the LightCycler MRSA Advanced Test with LightCycler 2.0 primer (Roche Molecular Biochemicals, Germany). To determine staphylococcal enterotoxins, the test system RIDASCREENSET A, B, C, D, E (R-Biopharm AG, Darmstadt, Germany) was used. We isolated saprophyte staphylococci from milk of raw and dairy products in western regions of Ukraine in 82.7$97.4 \%$ of samples. $S$. aureus is much more rarely isolated from these dairy products, so it was isolated from sour cream at $62.8 \pm 0.9 \%$, from milk at $35.5 \pm 1.3 \%$ and cottage cheese at $23.0 \pm 1.6 \%$. Of the most well known biotypes of S. aureus present in milk of raw and dairy products of domestic production, two ecological types were distinguished: human and cattle. In this case S. aureus var. hominis was isolated more often than in S. aureus var. bovis. This gives grounds to believe that the main source of contamination with milk staphylococci of raw and dairy products of domestic production is people. Enterotoxin type A, which causes foodborne toxemia, was produced by S. aureus in $40.0 \pm 0.5 \%$ of cases. Consequently, home-produced dairy products can spread staphylococcal toxicity caused by $S$. aureus var. hominis. It was found that $17.8 \pm 0.6 \%$ of $S$. aureus var. hominis were resistant to methicillin, which is 1.8 times greater than that of $S$. aureus var. bovis. This gives grounds to consider that there is a risk of MRSA infection to consumers of home-produced dairy products. All methicillin-resistant staphylococci studied produced enterotoxins.

Keywords: staphylococci; biotypes; MRSA; enterotoxins

\section{Биотиповые характеристики золотистых стафилококков, выделенных из молока и молочных продуктов домашнего производства в западных регионах Украины}

\author{
Н. Д. Кухтын*, Ю. В. Горюк**, В. В. Горюк**, Т. Я. Ярошенко***, О. И. Вичко*, О. С. Покотило* \\ *Тернопольский национальный технический университет имени Ивана Пулюя, Тернополь, Украина \\ **Подольский государственный аграрно-технический университет, Каменеи-Подольский, Украина \\ ***Тернопольский государственный медииинский университет имени И. Я. Горбачевского, Тернополь, Украина
}

Молочные продукты домашнего производства, которые реализуются на рынках в западных регионах Украины, не исследуются по микробиологическим показателям в полном объеме. Поэтому периодически эта продукция становится причиной возникновения у людей различных пищевых отравлений. Чаще всего при употреблении молочных продуктов домашнего производства, которые реализуются без соблюдения санитарно-гигиенических требований, возникают стафилококковые токсикозы. Среди значительного количества видов 
стафилококков энтеротоксины продуцирует в основном золотистый стафилококк. В статье приведены данные об обсемененности молока и молочных продуктов домашнего производства стафилококками, их биологическое происхождение, продукция энтеротоксинов, наличие метициллин-резистентных Staphylococcus aureus (MRSA). Определено наличие золотистых стафилококков в молоке сыром в 35,5\% случаев, в сметане и твороге - в 23,0-62,8\% случаев. Биотипирование $S$. aureus показало, что из молока сырого человеческий эковар выделен в 56,5\% случаев, из молочных продуктов (сметаны и творога) - 67,2-90,6\%, а из рук продавцов - в 93,2\%. Данные исследования указывают, что главный источник обсеменения молока и молочных продуктов золотистым стафилококком - люди, которые производят и реализуют продукцию. В значительно большем количестве определено наличие метициллин-резистентных культур у золотистого стафилококка человеческого биотипа по сравнению с биотипом крупного рогатого скота. 17,8\% культур S. aureus var. hominis были устойчивы к метициллину, что в 1,8 раза больше по сравнению с культурами $S$. aureus var. bovis. Это дает возможность предполагать инфицирование потребителей молочных продуктов домашнего производства MRSA. Энтеротоксин типа А, который вызывает стафилококковый токсикоз у людей, продуцирует только золотистый стафилококк человеческого биотипа.

Ключевые слова: стафилококки; биотипы; MRSA; энтеротоксины

\section{Введение}

Профилактика заболеваний пищевого происхождения относится к приоритетным задачам системы здравоохранения во всем мире (Cremonesi et al., 2007; Wang et al., 2009; Ateba et al., 2010; Thaker et al., 2013; Basanisi et al., 2017). В процессе изготовления молока и молочных продуктов главным фактором опасности является обсеменение патогенной и условно-патогенной микрофлорой (Doulgeraki et al., 2017; Mehli et al., 2017). Особую опасность представляют сальмонеллы, кишечные палочки, листерии и другие микроорганизмы, которые размножаются в молочных продуктах, не меняя их органолептических свойств (Lowy, 1998). Золотистый стафилококк является оппортунистическим условно-патогенным микроорганизмом, который часто обсеменяет сырое молоко и молочные продукты (Jaber et al., 2015; Carfora et al., 2015; Basanisi et al., 2017).

Среди большого количества видов стафилококков в основном S. aureus продуцирует энтеротоксины типа А, вызывающие пищевой токсикоз (Cremonesi et al., 2007; Thaker et al., 2013; Habib et al., 2015; Al-Ashmawy et al., 2016; Macori et al., 2016). В то же время, энтеротоксигенные штаммы $S$. aureus, изолированные от людей, по некоторым свойствам отличаются от штаммов $S$. aureus, выделенных от животных. Поэтому определяют несколько эковаров (биотипов) S. aureus в зависимости от биологического происхождения: S. aureus var. hominis, S. aureus var. avium, S. aureus var. canis, S. aureus var. bovis (Fournier et al., 2008; Jaber, 2011; Bardiau et al., 2013). В Украине научных работ, посвященных изучению биотипов золотистого стафилококка, выделенных из молока и молочных продуктов, практически нет. Ученые ограничиваются констатацией факта наличия этих бактерий в молочных продуктах без определения источника заражения, что не дает возможности предпринимать целенаправленные профилактические меры.

Также актуальным остается изучение распространенности метициллин-резистентного стафилококка (MRSA) в молоке и молочных продуктах (Kwon et al., 2005; Crago et al., 2012; Wang et al., 2014; Doulgeraki et al., 2017; Hamid et al., 2017; Macori et al., 2017). Низкий уровень его выделения из продуктов питания в Украине не отражает реальной ситуации. Внимание уделяется информации о чувствительности культур к антибиотикам с целью проведения лечебно-профилактических мероприятий, в то же время, распространение энтеротоксигенных штаммов не исследуется.

Таким образом, цель работы - определить источник контаминации молока и молочных продуктов домашнего производства в западных регионах Украины золотистым стафилококком, его способности продуцировать энтеротоксины, исследовать его метициллин-резистентные штаммы, что даст возможность разработать новые подходы к оценке микробиологической безопасности этих продуктов за счет усовершенствования нормативно-методической базы контроля.

\section{Материал и методы исследований}

Исследована 71 проба молока сырого, 212 проб сметаны, 65 проб творога домашнего производства, которые реализовались на продовольственных рынках западных регионов Украи- ны (Тернопольская, Хмельницкая, Львовская, Черновицкая области) и 57 смывов с рук продавцов этих продуктов. Выделено и идентифицировано 247 культур S. aureus.

Изоляция и идентификация золотистого стафилококка. Микробиологическую обработку образцов для выделения S. $a u-$ reus проводили с использованием BD Baird-Parker Agar по стандартной методике. Десятикратные разведения проб продуктов высевали на чашки для первичной изоляции. Инкубировали в аэробных условиях в течение $42-48$ ч при температуре $36 \pm 1{ }^{\circ} \mathrm{C}$ и делали подсчет через 18-24 и 42-48 часов.

Морфологические характеристики. Микроскопический препарат изготавливали с изолированной культуры на чистом предметном стекле и окрашивали по Граму. Окрашенный мазок исследовали под микроскопом: наблюдали грамположительные сферические клетки, похожие на гроздь винограда, расположенные в нескольких плоскостях.

Биохимическое исследование. Для подтверждения наличия S. aureus использовали тесты на каталазу, коагулазу, оксидазу, на ферментацию D-маннитола, продукцию ДНКазы, ацетоина (Maurin, 2004).

Oпределение биотипа. У культур, принадлежащих к S. aureus, биотип определяли используя схему: определение цвета пигмента, наличие бета-гемолиза, активность коагулазы в бычьей плазме, рост на среде с кристаллическим фиолетовым (Mayer, 1999).

Определение метициллин-резистентных стафилококков (MRSA). Для определения MRSA использовали хромогенную среду Агар chromID MRSA («Biomerioux», Россия). Определение гена тесА проводили с использованием тестовой системы LightCycler MRSA Advanced Test c помощью праймеров LightCycler 2.0 («Roche Molecular Biochemicals», Германия).

Обнаружение стафилококковых энтеротоксинов (SE). Для выявления энтеротоксинов штаммы культивировали в $10 \mathrm{~cm}^{3}$ питательного бульона («Merck», Германия) в течение суток в аэробных условиях при $37^{\circ} \mathrm{C}$. Супернатанты бактериальной культуры собирали центрифугированием при 4000 об./мин. в течение 10 мин. Для определения энтеротоксинов стафилококка SEA, SEB, SEC, SED и SEE использовали тест-систему Ridascreen ${ }^{\circledR}$ Set A, B, C, D, E («R-Biopharm AG», Германия). Анализ проводили согласно с методическими указаниями 4.2. 2429 - 08 «Метод определения стафилококковых энтеротоксинов в пищевых продуктах». Средний нижний предел обнаружения анализа составлял $0,1 \mathrm{Mг} / \mathrm{cm}^{3}$. Все эксперименты выполнялись в трехкратном повторении.

\section{Результаты}

Исследовано молоко сырое и молочные продукты домашнего производства, реализуемые на рынках западных регионов Украины, на обсемененность представителями рода Staphylococcus и его коагулазоположительным видом - S. aureus (табл. 1). Бактерии рода Staphylococcus по частоте выделения можно отнести к специфической микрофлоре молока сырого и молочных продуктов домашнего производства, так как они выделялись в $82,7-97,4 \%$ случаев. В то же время S. aureus в этих продуктах обнаруживался значительно реже. Чаще всего его выделяли из сметаны: $62,8 \%$ случаев, что в 1,8 раза $(\mathrm{P}<0,05)$ больше по сравнению с пробами молока сырого и в 2,7 раза больше $(\mathrm{P}<0,05)$ по сравнению с творогом. 
В молоке сыром и молочных продуктах домашнего производства (табл. 2) циркулируют два биотипа золотистого стафилококка: S. aureus var. bovis (биотип крупного рогатого скота) и S. aureus var. hominis (человеческий биотип). Однако доля их выделения из данных продуктов разная. Из молока сырого выделяли 43,5\% культур золотистого стафилококка, которые отнесены к биотипу крупного рогатого скота, а $56,5 \%$ - к человеческому эковару. Из сметаны выделялось $67,2 \%$ культур S. aureus var. hominis, что в 2,0 раза $(\mathrm{P}<0,05)$ больше, по сравнению co $S$. aureus var. bovis. С творога, в основном, выделялись бактерии $S$. aureus var. hominis. Их количество было в 1,6 раза $(\mathrm{P}<0,05)$ больше, чем в молоке. Количество бактерий S. aureus var. bovis в твороге было меньше в 4,6 раза $(\mathrm{P}<0,05)$ по сравнению с молоком. Доминирование человеческого эковара в твороге связано с обсеменением его после изготовления (при упаковке и реализации). Специфика изготовления творога в домашних условиях заключается в длительной термической обработке сквашенного молока, при которой погибает практически вся вегетативная микрофлора, в том числе и золотистый стафилококк. На руках продавцов преобладал человеческий биотип, который выделялся в $93,2 \pm 1,4 \%$ случаев, это указывает на то, что люди - главный источник обсеменения молочных продуктов золотистыми стафилококками.

\section{Таблица 1}

Обсемененность стафилококками молока и молочных продуктов домашнего производства в западных регионах Украины $(\%, \mathrm{n}=348)$

\begin{tabular}{lcc}
\hline \multirow{2}{*}{ Объект исследований } & \multicolumn{2}{c}{ Частота выделения стафилококков } \\
\cline { 2 - 3 } & Staphylococcus spp. & S. aureus \\
\hline Молоко сырое, $\mathrm{n}=71$ & 97,4 & 35,5 \\
Сметана, $\mathrm{n}=212$ & 98,7 & $62,8^{*}$ \\
Творог, $\mathrm{n}=65$ & 82,7 & 23,0 \\
\hline
\end{tabular}

Примечание: Staphylococcus spp. - все виды рода Staphylococcus; * $-\mathrm{P}<0,05$ по сравнению с пробами молока сырого и творога.

\section{Таблица 2}

Биотипы S. aureus, выделенные из молока и молочных продуктов домашнего производства в западных регионах Украины $(\%, \mathrm{n}=247)$

\begin{tabular}{lccc}
\hline \multirow{2}{*}{ Объект исследований } & \multirow{2}{*}{$\begin{array}{c}\text { Исследовано } \\
\text { культур, } \mathrm{n}\end{array}$} & $\begin{array}{c}\text { Биотипы Staphylococcus aureus } \\
\text { var. hominis }\end{array}$ & $\begin{array}{c}\text { S. aureus } \\
\text { var. bovis }\end{array}$ \\
\hline Молоко сырое & 51 & 56,5 & 43,5 \\
Сметана & 97 & $67,2^{*}$ & 32,8 \\
Творог & 43 & $90,6^{\#}$ & 9,4 \\
Смывы с рук продавцов & 56 & 93,2 & $6,8^{\Delta}$ \\
\hline
\end{tabular}

Примечание: S. aureus var. hominis - человеческий биотип (эковар); S. aureus var. bovis - биотип (эковар) крупного рогатого скота; * $-\mathrm{P}<0,05$ по сравнению с $S$. aureus var. bovis; \# - $\mathrm{P}<0,05$ по сравнению с молоком; $\Delta-\mathrm{P}<0,05$ по сравнению с молоком.

Таким образом, полученные данные биологического типирования золотистого стафилококка, который выделяли из молока сырого и молочных продуктов домашнего производства в западных регионах Украины, указывают на наличие постоянного источника обсеменения молочных продуктов бактериями S. aureus var. hominis от производителей и продавцов этих продуктов. Это требует постоянного микробиологического обследования производителей и продавцов для выявления их носительства и лечения с целью профилактики пищевых токсикозов стафилококковой этиологии.

Определение штаммов стафилококков, устойчивых к метициллину (табл. 3), показало, что оба биотипа резистентны к антибиотикам бета-лактамной группы: 17,8\% культур S. aureus var. hominis устойчивы к метициллину, что в 1,8 раза $(\mathrm{P}<0,05)$ больше по сравнению с культурами $S$. aureus var. bovis. Это дает основание полагать о возможности инфицирования потребителей молочных продуктов домашнего производства MRSA.
Стафилококки продуцируют шесть антигенных вариантов энтеротоксина: А, В, С, D, Е и F. В основном пищевой токсикоз вызывает энтеротоксин типа A, peже - D (Normanno et al., 2007). Нами определены продукция энтеротоксинов и их типы у бактерий S. aureus var. bovis и S. aureus var. hominis (табл. 4).

\section{Таблица 3}

Частота выделения метициллин-резистентных штаммов золотистого стафилококка из молока и молочных продуктов домашнего производства в западных регионах Украины $(\%, \mathrm{n}=247)$

\begin{tabular}{lcccc}
\hline Биотипы Staphylococcus & \multicolumn{1}{c}{ Исследовано культур } & \multicolumn{2}{c}{ Количество MRSA } \\
\cline { 2 - 5 } \multicolumn{1}{c}{ aureus } & $\mathrm{n}$ & $\%$ & $\mathrm{n}$ & $\%$ \\
\hline S. aureus var. hominis & 185 & 100 & 33 & $17,8^{*}$ \\
S. aureus var. bovis & 62 & 100 & 6 & 9,6 \\
\hline
\end{tabular}

Примечание: MRSA - метициллин-резистентный золотистый стафилококк; * - $\mathrm{P}<0,05$ по сравнению с $S$. aureus var. bovis.

\section{Таблица 4}

Типы энтеротоксинов, которые продуцировали золотистые стафилококки, выделенные из молока и молочных продуктов в западных регионах Украины $(\%, \mathrm{n}=247)$

\begin{tabular}{|c|c|c|c|c|}
\hline \multirow{2}{*}{$\begin{array}{c}\text { Типы } \\
\text { энтеротоксинов }\end{array}$} & \multicolumn{2}{|c|}{ S. aureus var. hominis } & \multicolumn{2}{|c|}{ S. aureus var. bovis } \\
\hline & $\begin{array}{l}\text { иследовано } \\
\text { культур, \% }\end{array}$ & $\begin{array}{c}\text { в том числе } \\
M R S A, \%\end{array}$ & $\begin{array}{l}\text { иследовано } \\
\text { культур, \% }\end{array}$ & $\begin{array}{c}\text { в том числе } \\
M R S A, \%\end{array}$ \\
\hline энтеротоксинов & & & & \\
\hline не продуцируют & 42,7 & 0 & 51,2 & 0 \\
\hline SEA & 40,0 & 85,1 & 0 & 0 \\
\hline SEB & 0 & 0 & 0 & 0 \\
\hline SEC & $12,4^{*}$ & 4,3 & 9,7 & 33,3 \\
\hline SED & $4,9 *$ & 11,1 & 12,9 & 12,5 \\
\hline SEC/D & 0 & 0 & 24,2 & 60,0 \\
\hline
\end{tabular}

Примечание: SEA - энтеротоксины типа А, SEB - энтеротоксины типа B, SEC - энтеротоксины типа C, SED - энтеротоксины типа D, SEC/D смешанные энтеротоксины типа С и $\mathrm{D} ; *-\mathrm{P}<0,05$ по сравнению с S. aureus var. bovis.

Количество штаммов $S$. aureus var. hominis и $S$. aureus var. bovis, которые вообще не продуцировали энтеротоксинов, составляла соответственно 42,7\% и 51,6\%. Способность продуцировать энтеротоксин типа А обнаружили только в 40,0\% бактерий S. aureus var. hominis. Количество бактерий S. aureus var. hominis, которые продуцировали энтеротоксин типа C, составляло $12,4 \%$, что в 1,3 раза $(\mathrm{P}<0,05)$ больше по сравнению co $S$. aureus var. bovis. Энтеротоксин типа D бактерии S. aureus var. hominis продуцировали в 2,6 раза $(\mathrm{P}<0,05)$ меньше, чем бактерии $S$. aureus var. bovis. Смешанные типы энтеротоксинов C/D продуцировали только бактерии S. aureus var. bovis в $24,2 \%$ случаев. Все выделенные MRSA - энтеротоксигенные. Таким образом, энтеротоксин типа A, который в основном вызывает пищевое отравление, продуцирует в молоке и молочных продуктах золотистый стафилококк человеческого происхождения.

\section{Обсуждение}

Почти $100 \%$ наличие бактерий рода Staphylococcus в пробах молочных продуктов домашнего производства можно объяснить тем, что эти молочные продукты изготавливаются из сырого термически не обработанного молока коров с нарушением санитарно-гигиенических норм и правил. Стафилококки составляют так называемую резидентную (полезную) микрофлору кожи вымени коров и почти всегда их можно выделить из сырого молока (Febler et al., 2010; Anderson et al., 2012; Mahmmod et al., 2017, Kukhtyn et al., 2017). Поэтому сапрофитные стафилококки часто выделяются из необработанных молочных продуктов домашнего производства. Золотистые стафилококки, по данным исследований, значительно реже выделяются с поверхности кожи сосков и молочной железы у здоровых коров. Около 20\% клинически здоровых коров являются их носителями на поверхности кожи сосков и до $5 \%$ - в молочной железе. Однако их 
количество существенно возрастает в сыром молоке при мастите, наличии ран, царапин и эрозий кожи сосков (Graber et al., 2009; Anderson et al., 2012; Carfora et al., 2015). Таким образом, некоторая обсемененность молочных продуктов домашнего производства сапрофитными коагулазоотрицательными стафилококками - это закономерность, которую нельзя избежать, так как они присутствуют на коже сосков коров и в молоке сыром. В то же время выделение золотистого стафилококка, в частности, биотипа крупного рогатого скота, будет свидетельствовать о наличии заболеваний кожи вымени или молочной железы коров.

Из наиболее известных биотипов золотистого стафилококка (S. aureus var. hominis, S. aureus var bovis, S. aureus var. avium, S. aureus var. canis) (Fournier et al., 2008; Jaber, 2011; Bardiau et al., 2013), с молока сырого и молочных продуктов домашнего производства выделяли два эковара: человеческий и крупного рогатого скота. При этом S. aureus var. hominis выделяли чаще по сравнению co $S$. aureus var bovis. Это дает основание считать, что главным источником обсеменения стафилококками молока сырого и молочных продуктов домашнего производства являяются люди, которые не соблюдают надлежащей гигиены и санитарии во время производственных процессов: доения коров, первичной обработки молока, изготовления и реализации молочных продуктов. Такая значительная обсемененность коагулазоположительными стафилококками не может остаться без внимания из-за возможности их размножаться и продуцировать энтеротоксины, которые способны вызывать пищевые отравления. Считается, что молочные продукты контаминированны преимущественно стафилококками биотипа крупного рогатого скота (Normanno et al., 2007; Jaber et al., 2015; Bharathy et al., 2015), в то же время большинство случаев стафилококковых пищевых токсикозов вызывают энтеротоксины типа А и D, которые продуцируют стафилококки человеческого биотипа (Davis et al., 2004; Argudin et al., 2010; Doulgeraki et al., 2017).

Считается, что мультирезистентный золотистый стафилокок является одним из наиболее распространенных возбудителей нозокоминальных инфекций в Европе и мире (Paterson et al., 2014; Sergelidis and Angelidis, 2015; Basanisi et al., 2017). В настоящее время в Украине нет научных результатов исследований о распространенности этого возбудителя в молочных продуктах домашнего производства. Проведенные нами исследования показали, что оба биотипа $S$. aureus var. hominis и $S$. aureus var. bovis были резистентными к антибиотикам бета-лактамной группы. В 17,9\% случаев MRSA имел человеческое происхождение, что в 1,8 раза больше по сравнению с биотипом крупного рогатого скота. Это дает основание полагать о возможности инфицирования потребителей молочных продуктов домашнего производства MRSA, поскольку все исследованные культуры MRSA продуцировали энтеротоксины.

Проведенные исследования показали, что энтеротоксин типа А продуцировал только S. aureus var. hominis. Среди всех энтеротоксинов тип А выделялся в 40,1\% случаев. Культуры стафилококков биотипа крупного рогатого скота продуцировали, в основном, токсины типов C, D и C/D, что, скорее всего, свидетельствует о проявлениях клинических и субклинических форм маститов у коров (Febler et al., 2010; Habib et al., 2015). Следовательно, молочные продукты домашнего производства могут быть причиной возникновения стафилококкового токсикоза, который вызывает S. aureus var. hominis.

Полученные новые данные об источниках обсеменения молока и молочных продуктов домашнего производства энтеротоксигенными штаммами золотистого стафилококка человеческого биотипа указывают на необходимость комплексного подхода к разработке микробиологических критериев безопасности. Информация о возможных источниках обсеменения необработанных молочных продуктов домашнего производства золотистым стафилококком и их контроль являются залогом эффективной профилактики пищевых токсикозов стафилококковой этиологии.

\section{Выводы}

Из молока и молочных продуктов домашнего производства в западных регионах Украины выделяются два биотипа золотистого стафилококка: $S$. aureus var. hominis и $S$. aureus var. bovis. Золотистый стафилококк человеческого биотипа содержится в этих продуктах в значительно большем количестве и попадает в них с рук производителей и продавцов при несоблюдении правил гигиены. 17,8\% культур $S$. aureus var. hominis устойчивы к метициллину, что в 1,8 раза $(\mathrm{P}<0,05)$ больше по сравнению с культурами $S$. aureus var. bovis. Энтеротоксин типа А, который вызывает стафилококковый токсикоз, продуцируют только культуры S. aureus var. hominis. Учитывая установленные новые источники обсеменения золотистым стафилококком молочных продуктов домашнего производства и с целью профилактики пищевых токсикозов стафилококковой этиологии, необходимо усовершенствовать систему контроля этих продуктов от изготовления до реализации.

\section{References}

Al-Ashmawy, M. A., Sallam, K. I., Abd-Elghany, S. M., Elhadidy, M., \& Tamura, T. (2016). Prevalence, molecular characterization, and antimicrobial susceptibility of methicillin-resistant Staphylococcus aureus isolated from milk and dairy products. Foodborne Pathogens and Disease, 13(3), 156-162.

Anderson, K. L., Lyman, R., Moury, K., Ray, D., Watson, D. W., \& Correa, M. T. (2012). Molecular epidemiology of Staphylococcus aureus mastitis in dairy heifers. Journal of Dairy Science, 95(9), 4921-4930.

Argudin, M. A., Mendoza, M. C., \& Rodicio, M. R. (2010). Food poisoning and Staphylococcus aureus enterotoxins. Toxins, 2, 1751-1773.

Ateba, C. N., Mbewe, M., Moneoang, M. S., \& Bezuidenhout, C. C. (2010). Antibiotic-resistant Staphylococcus aureus isolated from milk in the Mafikeng Area, North West province, South Africa. South African Journal of Science, 106(11-12), 1-6.

Bardiau, M., Yamazaki, K., Duprez, J. N., Taminiau, B., Mainil, J. G., \& Ote, I. (2013). Genotypic and phenotypic characterization of methicillin resistant Staphylococcus aureus (MRSA) isolated from milk of bovine mastitis. Letters in Applied Microbiology, 57(3), 181-186.

Basanisi, M. G., La Bella, G., Nobili, G., Franconieri, I., \& La Salandra, G. (2017). Genotyping of methicillin-resistant Staphylococcus aureus (MRSA) isolated from milk and dairy products in South Italy. Food Microbiology, 62, 141-146.

Bharathy, S., Gunaseelan, L., Porteen, K., \& Bojiraj, M. (2015). Prevalence of Staphylococcus aureus in raw milk: Can it be a potential public health threat. International Journal of Advanced Research, 3(2), 801-806.

Carfora, V., Caprioli, A., Marri, N., Sagrafoli, D., Boselli, C., Giacinti, G., Sorbara L., Dottarelli S., Battisti A., \& Amatiste, S. (2015). Enterotoxin genes, enterotoxin production, and methicillin resistance in Staphylococcus aureus isolated from milk and dairy products in Central Italy. International Dairy Journal, 42, 12-15.

Crago, B., Ferrato, C., Drews, S. J., Svenson, L. W., Tyrrell, G., \& Louie, M. (2012). Prevalence of Staphylococcus aureus and methicillin-resistant $S$. aureus (MRSA) in food samples associated with foodborne illness in Alberta, Canada from 2007 to 2010. Food Microbiology, 32(1), 202-205.

Cremonesi, P., Perez, G., Pisoni, G., Moroni, P., Morandi, S., Luzzana, M., Brasca, M., \& Castiglioni, B. (2007). Detection of enterotoxigenic Staphylococcus aureus isolates in raw milk cheese. Letters in applied microbiology, 45(6), 586-591.

Davis, K. A., Stewart, J. J., Crouch, H. K., Florez, C. E., \& Hospenthal, D. R. (2004). Methicillin-resistant Staphylococcus aureus (MRSA) nares colonization at hospital admission and its effect on subsequent MRSA infection. Clinical Infectious Diseases, 39(6), 776-782.

Doulgeraki, A. I., Di Ciccio, P., Ianieri, A., \& Nychas, G. J. E. (2017). Methicillin-resistant food-related Staphylococcus aureus: A review of current knowledge and biofilm formation for future studies and applications. Research in Microbiology, 168(1), 1-15.

Febler, A., Scott, C., Kadlec, K., Ehricht, R., Monecke, S., \& Schwarz, S. (2010). Characterization of methicillin-resistant Staphylococcus aureus ST-398 from cases of bovine mastitis. Journal of Antimicrobial Chemotherapy, 65(4), 619-625.

Fournier, C., Kuhnert, P., Frey, J., Miserez, R., Kirchhofer, M., Kaufmann, T., Stener, A., \& Graber, H. U. (2008). Bovine Staphylococcus aureus: association of virulence genes, genotypes and clinical outcome. Research in Veterinary Science, 85, 439-448. 
Graber, H. U., Naskova, J., Studer, E., Kaufmann, T., Kirchhofer, M., Brechbühl, M., Schaeren, W., A. Steiner, A., \& Fournier, C. (2009). Mastitisrelated subtypes of bovine Staphylococcus aureus are characterized by different clinical properties. Journal of Dairy Science, 92, 1442-1451.

Habib, F., Rind, R., Durani, N., Bhutto, A. L., Buriro, R. S., Tunio, A., Aijaz, N., Lakho, S. A., Bugti, A. G., \& Shoaib, M. (2015). Morphological and cultural characterization of Staphylococcus aureus isolated from differrent animal species. Journal of Applied Environmental and Biological Sciences, 5(2), 15-26.

Hamid, S., Bhat, M. A., Mir, I. A., Taku, A., Badroo, G. A., Nazki, S., \& Malik, A. (2017). Phenotypic and genotypic characterization of methicillin-resistant Staphylococcus aureus from bovine mastitis. Veterinary World, 10(3), 363-367.

Jaber, S., Weder, D., Bridy, C., Huguenin, M. C., Robert, L., Hummerjohann, J., \& Stephan, R. (2015). Outbreak of staphylococcal food poisoning among children and staff at a Swiss boarding school due to soft cheese made from raw milk. Journal of Dairy Science, 98, 2944-2948.

Jaber, N. N. (2011). Isolation and biotyping of Staphylococcus aureus from white cheese in Basrah local markets. Basrah Journal of Veterinary Research, 10(2), 55-66.

Kukhtyn, M. D., Kovalenko, V. L., Pokotylo, O. S., Horyuk, Y. V., Horyuk, V. V., \& Pokotylo, O. O. (2017) Staphylococcal contamination of raw milk and handmade dairy products, which are realized at the markets of Ukraine. Journal for Veterinary Medicine, Biotechnology and Biosafety, 3(1), 12-16.

Kwon, N. H., Park, K. T., Moon, J. S., Jung, W. K., Kim, S. H., Kim, J. M., Hong, S. K., Koo, H. C., Joo, Y S., \& Park, Y. H. (2005). Staphylococcal cassette chromosome mec (SCC mec) characterization and molecular analysis for methicillin-resistant Staphylococcus aureus and novel SCC mec subtype IVg isolated from bovine milk in Korea. Journal of Antimicrobial Chemotherapy, 56(4), 624-632.

Lowy, F. D. (1998). Staphylococcus aureus infections. New England Journal of Medicine, 339(8), 520-532.

Macori, G., Bellio, A., Bianchi, D. M., Gallina, S., Adriano, D., Zuccon, F., Chiesa, F., Acutis, P. L., Casalinuovo, F., \& Decastelli, L. (2016). Molecular typing of Staphylococcus aureus isolate responsible for staphylococcal poisoning incident in homemade food. Italian Journal of Food Safety, 5(2), 5736.

Macori, G., Giacinti, G., Bellio, A., Gallina, S., Bianchi, D. M., Sagrafoli, D., Marri, N., Giangolini, G., Amatiste, S., \& Decastelli, L. (2017). Molecular epidemiology of methicillin-resistant and methicillin-susceptible Staphylo- coccus aureus in the ovine dairy chain and in farm-related humans. Toxins, 9(5), 161.

Mahmmod, Y. S., Klaas, I. C., \& Enevoldsen, C. (2017). DNA carryover in milk samples from routine milk recording used for PCR-based diagnosis of bovine Staphylococcus aureus mastitis. Journal of Dairy Science, 100(7), 5709-5716.

Maurin, F., Mazerolles, G., Noel, Y., \& Kodjo, A. (2004). Identification and biotyping of coagulase positive staphylococci (CPS) in ripened French raw milk cheeses and their in vitro ability to produce enterotoxins. Revue de Medecine Veterinaire, 155(2), 92-96.

Mayer, S. (1999). Eingenschaften von aus Kuhmilch isolaten Staphylokokken in Hinblick auf die Beurteilung von Milch. Milchwissenschaft, 30, 607-608.

Mehli, L., Hoel, S., Thomassen, G. M. B., Jakobsen, A. N., \& Karlsen, H. (2017). The prevalence, genetic diversity and antibiotic resistance of Staphylococcus aureus in milk, whey, and cheese from artisan farm dairies. International Dairy Journal, 65, 20-27.

Normanno, G. L., Salandra, A., Dambrosio, N. C., Quaglia, M., Corrente, A., Parisi, G., Santagada, A., Firinu, E., \& Crisetti, G. V. (2007). Occurrence, characterization and antimicrobial resistance of enterotoxigenic Staphylococcus aureus isolated from meat and dairy products. International Journal of Food Microbiology, 115(3), 290-296.

Paterson, G. K., Harrison, E. M., \& Holmes, M. A. (2014). The emergence of mecC methicillin-resistant Staphylococcus aureus. Trends in Microbiology, 22(1), 42-47.

Sergelidis, D., \& Angelidis, A. S. (2017). Methicillin resistant Staphylococcus aureus (MRSA): A controversial food borne pathogen. Letters in Applied Microbiology, 64(6), 409-418.

Thaker, H. C., Brahmbhatt, M. N., Nayak, J. B., \& Thaker, H. C. (2013). Isolation and identification of Staphylococcus aureus from milk and milk products and their drug resistance patterns in Anand, Gujarat. Veterinary World, 6(1), 10-13.

Wang, S. C., Wu, C. M., Xia, S. C., Yong-Hua, Q. I., Xia, L. N., \& Shen, J. Z. (2009). Distribution of superantigenic toxin genes in Staphylococcus aureus isolates from milk samples of bovine subclinical mastitis cases in two major diary production regions of China. Veterinary Microbiology, 137(3), 276-281.

Wang, X., Li, G., Xia, X., Yang, B., Xi, M., \& Meng, J. (2014). Antimicrobial susceptibility and molecular typing of methicillin-resistant Staphylococcus aureus in retail foods in Shaanxi, China. Foodborne Pathogens and Disease, 11(4), 281-286. 